\section{Bullous pemphigoid and radiotherapy: Case report and literature review update}

\author{
Antonio Piras, ${ }^{1}$ Bruno Fionda, ${ }^{2}$ \\ Antonella Sanfratello, ${ }^{3}$ Andrea \\ D'Aviero, ${ }^{2}$ Giovanni Sortino, ${ }^{4}$ \\ Gianfranco Pernice, ${ }^{4}$ Luca Boldrini, ${ }^{2,5}$ \\ Tommaso Angileri, ${ }^{6}$ Antonino Daidone ${ }^{1}$
}

${ }^{1}$ UO Radioterapia Oncologica, Villa Santa Teresa, Bagheria, Palermo, Italy; ${ }^{2}$ UOC Radioterapia Oncologica Fondazione Policlinico Universitario Agostino Gemelli IRCCS, Dipartimento di Diagnostica per immagini, Radioterapia Oncologica ed Ematologia, Rome, Italy; ${ }^{3}$ Università degli Studi di Palermo, Radioterapia Oncologica, Palermo, Italy; ${ }^{4} \mathrm{UO}$ Oncologia, Fondazione Istituto G. Giglio, Cefalù, Palermo; ${ }^{5}$ Università Cattolica del Sacro Cuore, Rome, Italy; 'UO Radiologia, Villa Santa Teresa, Bagheria, Palermo, Italy

\section{Abstract \\ Bullous pemphigoid (BP) is a common autoimmune bullous disease generally occurring in elderly patients. Itchy and tense blisters on normal skin or erythema- tous and edematous lesions on the trunk and extremities usually characterize BP. Trigger factors are still unclear while several case reports suggest a potential role of radiother- apy (RT) as BP trigger for disease onset or recrudescence. A review was performed to provide an update of literature. A case report of a patient affected by BP undergo- ing two radiotherapy courses for a primary breast cancer was also reported. A compre- hensive review of the published literature was conducted according to Preferred Reporting Items for Systematic Reviews and Meta-Analyses guidelines. The review included studies describing BP and its rela- tionships with RT treatments. A total of 13 articles were reviewed. Studies characteris- tics analysis resulted in eleven case reports, one case series and one large-scale case- control study. Literature update confirms the existence of a reasonable connection between RT and BP. Case report showed that a multidisciplinary management seems to assure the feasibility of RT in patients affected by BP, not depriving them of stan- dard therapeutic opportunities.}

\section{Introduction}

Bullous pemphigoid (BP) is the most common autoimmune bullous disease and generally occurs in elderly patients. ${ }^{1}$

The underlying pathophysiological mechanism is based on the presence of autoantibodies that recognize self-antigens at the level of the basement membrane, responsible for the adhesion between the epidermis and the dermis. Its trigger factors are still unclear and different conditions, such as psoriasis, lichen planus and drugs, may be involved in the pathogenesis. ${ }^{2}$

This condition usually affects elderly individuals and is often characterized by itchy and tense blisters on normal skin or erythematous and edematous lesions on the trunk and extremities. ${ }^{3}$

Disease localizations primarily affect the axillary folds, lower abdomen, groin areas and inner thighs. They can be either localized or widespread, while the involvement of the mucosae is reported in 10-30\% of cases with oral, esophageal and genital lesions. ${ }^{3}$

Besides the aforementioned possible causes, several case reports suggest a potential role of radiotherapy (RT) as BP trigger for disease onset or recrudescence. ${ }^{4-7}$

The first report of a RT-associated localized BP was documented by Duschet et al. ${ }^{8}$ in 1988 and the most recent review of $\mathrm{PB}$ cases linked to RT dates back to 2014, describing a total of 29 known cases. ${ }^{9}$

Aim of this paper is to provide an update of the available literature and to report the case of a patient affected by BP undergoing two radiotherapy courses for a primary breast cancer.

\section{Case Report}

The case of a 71-year-old woman diagnosed in 2008 with right breast Invasive Ductal Carcinoma (IDC), G3, triple negative with ki67 $80 \%$ and clinically staged cT2N0M0, is here presented.

The patient had a previous diagnosis of BP in 1991 after suffering a diffuse bullous eruption distributed to the upper and lower extremities and scalp with moderate pain.

A biopsy of the arm lesions was the performed and BP diagnosis was confirmed through histological examination. Direct immunofluorescence revealed linear typical deposition of complement $\mathrm{C} 3$ and $\mathrm{C} 4$ and immunoglobulins $\mathrm{G}$ (IgG) and $\mathrm{M}$ (IgM) along the dermo-epidermal junction.

BP was treated with Methylprednisolone $30 \mathrm{mg}$ daily, obtaining good response.
Correspondence: Andrea D'Aviero, UOC Radioterapia Oncologica - Fondazione Policlinico Universitario Agostino Gemelli IRCCS, Dipartimento di Diagnostica per immagini, Radioterapia Oncologica ed Ematologia, Largo Agostino Gemelli 8, 00168 Roma, Italy.

Tel.: +39.06.30154986.

E-mail: andrea.daviero@guest.policlinicogemelli.it

Key words: Bullous pemphigoid; Radiotherapy; Review; Personalized medicine.

Contributions: Conceptualization: AD; TA LB; AP. Methodology: AP; BF; AS; ADA Formal analysis: AP, BF. Data curation: AP; ADA; LD. Original draft preparation: AP; BF; AS; ADA. Review \& editing: GS; GP; LB; TA; AD. Supervision: AD; TA; LB. All authors read and approved the final article and gave consent for its publication.

Conflict of interest: The authors declare no potential conflict of interest.

Funding: None.

Data availability: The data presented in this study are available on request from the corresponding author.

Ethics approval: The study was conducted according to the guidelines of the declaration of Helsinki. Patients enrolled signed a consent for data collection according to the study design requirements

Informed consent statement: Informed consent was obtained from all subjects involved in the study.

Please cite this article as: Piras A, Fionda B, Sanfratello A, et al. Bullous pemphigoid and radiotherapy: Case report and literature review update. Dermatol Rep 2022; 14:9170.

Received for publication: 8 April 2021.

Accepted for publication: 14 September 2021

This work is licensed under a Creative Commons Attribution-NonCommercial 4.0 International License (CC BY-NC 4.0).

( ${ }^{C}$ Copyright: the Author(s), 2022

Licensee PAGEPress, Italy

Dermatology Reports 2022; 14:9170

doi:10.4081/dr.2022.9170

Publisher's note: All claims expressed in this article are solely those of the authors and do not necessarily represent those of their affiliated organizations, or those of the publisher, the editors and the reviewers. Any product that may be evaluated in this article or claim that may be made by its manufacturer is not guaranteed or endorsed by the publisher. 
Since 1991, the patient has continued Prednisone $5 \mathrm{mg}$ daily. In fact, during the brief periods in which she tried to stop the therapy, she had a recrudescence of the symptoms.

At the moment of breast cancer diagnosis, the patient was still undergoing a specific therapy for BP (Prednisone $5 \mathrm{mg}$, daily) and did not report any symptom.

According to disease staging, neo-adjuvant chemotherapy was administered with Epirubicin and Cyclophosphamide (EC) for 4 cycles on 3 weeks schedule, followed by 12 weekly cycles of Paclitaxel.

The patient then underwent right breast conservative surgery with sentinel lymph node biopsy in November 2018 and the pathological examination confirmed a residual IDC (ypT1a ypN0).

Adjuvant radiotherapy was then prescribed on the residual right breast (50 Gy in 25 fractions).

A tangential field with $6 \mathrm{MV}$ photons three-dimensional conformal radiotherapy
(3D-CRT) technique was chosen and a sequential boost to tumor bed was also performed (10 Gy in 5 fractions) with electronbeam $6 \mathrm{MeV}$.

Following the evidence of right axillary adenopathy diagnosed in April 2020, the patient underwent right axillary lymphnode dissection. Pathological examination confirmed the nodal metastases in 14/15 lymph-nodes. Adjuvant chemotherapy was administered with Cyclophosphamide, Methotrexate, 5 Fluorouracil (CMF) for 6 cycles and right clavicular-axillary nodal stations (50 Gy in 25 fractions) were irradiated in November 2020 with volumetricarc-Therapy (VMAT) technique.

Throughout this period BP maintenance therapy was continuously administered and regular dermatologic surveillance was performed.

The last visit on January 2021 reported no signs of active BP, despite the administered oncological treatments and the clinical history of the patient.

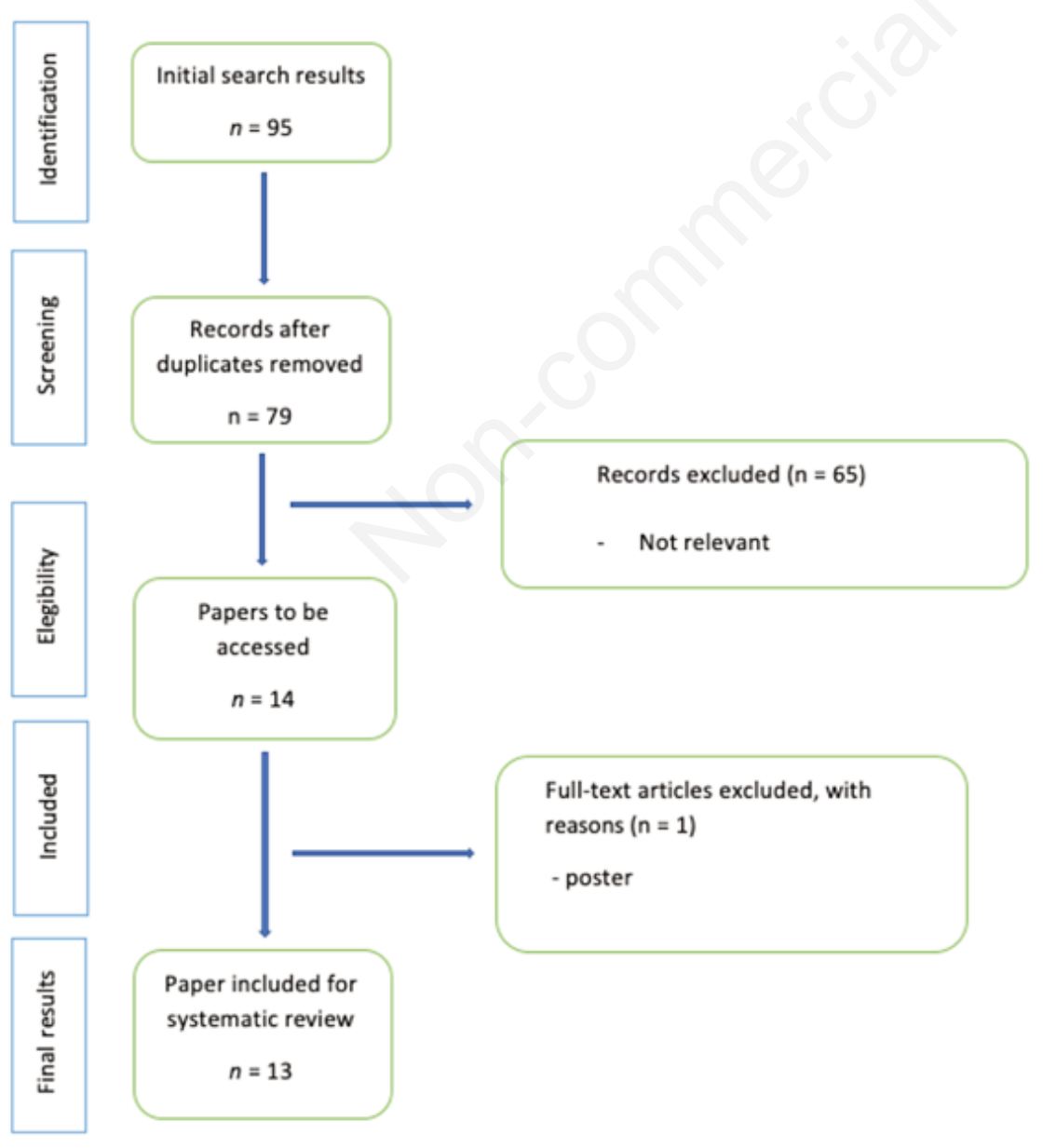

Figure 1. PRISMA diagram.

\section{Update of literature review}

A comprehensive review of the published literature was also performed for the purposes of this work. The search strategy implied the use of the terms "Pemphigoid" and "Radiotherapy" on PubMed and EMBASE databases. The considered time frame was set from 2014 to January 2021, as our primary aim was to update the work of Nguyen et al., avoiding unnecessary repetitions. $^{9}$

Case reports, case series, retrospective and prospective studies describing BP and its relationships with radiotherapy treatments were considered for the analysis.

Exclusion criteria were the following: papers not focused on BP, lack of sufficient details of the RT treatments, or papers not written in English.

The review was conducted according to the PRISMA guidelines, ${ }^{10}$ disclosing 95 papers with final result of 79 papers after duplicated removal.

After the first screening, 65 papers were excluded, as title and abstract were considered irrelevant to the relationship between RT and BP; 14 papers were lastly selected for an extensive analysis.

One of these was lastly excluded from the analysis, as it turned out to be a conference poster.

The PRISMA flowchart (Figure 1) describes the review workflow.

A total of 13 residual articles fulfilling the inclusion criteria were included in the present review update. Table 1 summarizes the main characteristics of the selected studies. $4-7,11-19$

Eleven articles are case reports, ${ }^{4-7,11,13-}$ $16,18,19$ while a case series of 2 patients was provided by Shon et al. ${ }^{12}$

Hung et al., ${ }^{17}$ reported the first largescale case-control study in 2019 , focusing on the relationship between the development of autoimmune blistering disease among patients mainly affected by breast cancer and treated with RT. The authors described 196 cases of BP and pemphigus vulgaris associated with RT and their findings suggest that RT is strongly associated with the risk of subsequently developing cutaneous blistering disorders. Most of the considered patients (90) were affected by breast cancer and most of the patients affected by BP, underwent a rapid and good response to specific treatments, which allowed them to achieve complete remission.

The preferred therapeutic options included topical corticosteroid application and systemic treatment using prednisolone or immunosuppressive agents. 
More in details, BP lesions typically appeared throughout an extremely variable time interval, ranging from diseases appearance during RT and up to 9 years after its end.

When investigating the relationships between irradiated site and BP appearance, it can be noticed that the lesions are generally not limited to the irradiation field only but, in most of the cases, this represented only their first site of appearance.

Treatment for RT-induced BP is similar to idiopathic BP, comprehending the use of topical and systemic corticosteroids, oral antibiotics, niacinamide and immunosup- pressive agents (i.e. mycophenolate mofetil or azathioprine). Anti-CD20 agents may also be considered for refractory cases. ${ }^{20,21}$

The prognosis of BP is overall good, but can be burdened by secondary infections leading to hospitalization due to the possible onset of sepsis, requiring oncological treatments discontinuation. ${ }^{2}$ A strict monitoring of patients should therefore be guaranteed during the whole RT treatment and in the follow up time, in order to promptly intervene in case of necessity.

\section{Conclusions}

The reported case suggests that RT in patients affected by BP could be feasible and should not deprive them of standard therapeutic opportunities.

The literature review and its update confirm the existence of a reasonable connection between RT and BP. Radiation oncologists should be aware of the correlation between RT and BP, to allow for rapid identification and proper management of possible disease onset or recrudescence.

A multidisciplinary management with a

Table 1. Studies characteristics.

\begin{tabular}{|c|c|c|c|c|c|c|c|}
\hline $\mathrm{N}$ & $\begin{array}{l}\text { Author } \\
\text { and year }\end{array}$ & $\begin{array}{l}\text { Type of } \\
\text { study }\end{array}$ & $\begin{array}{c}\mathrm{N} . \\
\text { patients }\end{array}$ & Target & $\begin{array}{l}\text { Dose for } \\
\text { fraction (fr) }\end{array}$ & $\begin{array}{l}\text { Time interval } \\
\text { during/after RT }\end{array}$ & Toxicity \\
\hline 1 & $\begin{array}{l}\text { Binitha } \\
2014\end{array}$ & Case report & 1 & Hypopharynx & 60 Gy for 26 days & 9 years & $\begin{array}{l}\text { Multipl hemorrhagic bullae and erosions, } \\
\text { with a few vesicles, were present on the dorsum } \\
\text { of the right hand and fingers, and the anterior } \\
\text { aspect of the right leg and ankle. Erosion in Oral } \\
\text { cavity. }\end{array}$ \\
\hline 2 & $\begin{array}{l}\text { Trombetta } \\
2015\end{array}$ & Case report & 1 & Breast & $\begin{array}{l}4256 \text { cGy at } 266 \text { cGy } \\
\text { per fraction }\end{array}$ & 2 months & $\begin{array}{l}\text { Tenderness and erythema } \\
\text { in the breast near the areola }\end{array}$ \\
\hline 3 & Nieder 2015 & Case report & 1 & $\begin{array}{l}\text { Mediastinal and left-sided } \\
\text { axillary lymph node } \\
\text { metastases }\end{array}$ & 30 Gy in 10 fr & During RT & $\begin{array}{l}\text { Bullous pemphigoid mainly involving trunk and } \\
\text { arms }\end{array}$ \\
\hline 4 & Campa 2016 & Case report & 1 & Partial breast & 34 Gy Brachyterapy & 5 months & $\begin{array}{l}\text { Painful, pruritic, erythematous rash on her left } \\
\text { breast with erosions and vesicles containing } \\
\text { cloudy and clear fluid }\end{array}$ \\
\hline 5 & Shon 2016 & Cases series & 2 & $\begin{array}{l}\text { - Cervical squamous carcinoma; } \\
\text { - Squamous cell carcinoma of } \\
\text { unknown origin on the neck }\end{array}$ & $\begin{array}{l}1 \\
1\end{array}$ & $\begin{array}{l}9 \text { months } \\
6 \text { motnhs }\end{array}$ & $\begin{array}{l}\text { - Generalized pruritic rash of } 1 \text { month's } \\
\text { duration and occasional blistering } \\
\text { without mucosal involvement } \\
\text { - A blistering eruption that had developed on the } \\
\text { neck, the upper part of the chest, and other body } \\
\text { sites, including the oral mucosa }\end{array}$ \\
\hline 6 & Kluger 2016 & Case report & 1 & Breast & $\begin{array}{l}40.05 \text { Gy in } 2.67 \\
\text { fractions }\end{array}$ & Less than a month & $\begin{array}{l}\text { Itchy vesicles and blisters appeared on the right } \\
\text { breast and led to larger hemorrhagic blisters } \\
\text { and erosions, on the extremities with a gloves } \\
\text { and socks disposition. }\end{array}$ \\
\hline 7 & Hirotsu 2017 & Case report & 1 & Pelvic nodal metastases & $48 \mathrm{~Gy}$ & 3 weeks & $\begin{array}{l}\text { Tense bullae localized to the right thigh within } \\
\text { the recent radiation treatment field }\end{array}$ \\
\hline 8 & Tanita 2018 & Case report & 1 & Second cervical vertebra & 45 Gy in 5 fractions & 7 weeks & $\begin{array}{l}\text { Large, tense bullae and erosion aris- ing on } \\
\text { erythematous plaque on the trunk and extremities }\end{array}$ \\
\hline 9 & Grimaux 2018 & Case report & 1 & Costal metastases & 30 Gy in 10 fractions & $\begin{array}{l}\text { A few hours after } \\
\text { the first session }\end{array}$ & $\begin{array}{l}\text { Small pruritic blisters appeared over } \\
\text { left hemi-thorax. These progressed } \\
\text { to very large postbullous mucosal erosions }\end{array}$ \\
\hline 10 & Hung 2019 & $\begin{array}{l}\text { Case-control } \\
\text { study }\end{array}$ & $196^{*}$ & $\begin{array}{l}90 \text { breast } \\
110 \text { others }\end{array}$ & l & l & l \\
\hline 11 & $\operatorname{Kim} 2020$ & Case report & 1 & $\begin{array}{l}\text { Whole-pelvis and } \\
\text { whole- brain radiotherapy } \\
\text { for } 3 \text { months }\end{array}$ & l & 8 months & Bullae and erosion in the right thigh \\
\hline 12 & Rejeb 2020 & Case report & 1 & Breast cancer & 50 Gy/25 fractions & 2 months & $\begin{array}{l}\text { Erythematous and pruritic vesicular eruption } \\
\text { developed initially in the irradiated area and } \\
\text { extended later on over other skin areas }\end{array}$ \\
\hline 13 & Palleschi 2020 & Case report & 1 & Laryngeal cancer & I & 6 years & $\begin{array}{l}\text { Multiple areas of blisters, erosions, and } \\
\text { pseudomembranes on the epiglottis and } \\
\text { aryepiglottic folds }\end{array}$ \\
\hline
\end{tabular}

*Bullous pemphigoid and pemphigus vulgaris. 
referral dermatologist during oncological therapies is therefore strongly encouraged when the anamnestic evidence of BP is known.

\section{References}

1. Bernard P, Antonicelli F. Bullous Pemphigoid: A Review of its Diagnosis, Associations and Treatment. Am J Clin Dermatol 2017;18:513-28.

2. Schmidt E, Zillikens D. Pemphigoid diseases. Lancet 2013;381:320-32.

3. Miyamoto D, Santi CG, Aoki V, Maruta CW. Bullous pemphigoid. An Bras Dermatol 2019;94:133-46.

4. Binitha MP, Vishnu VV, Sreekanth S, Reena Mariyath OK. Localized bullous pemphigoid on sites of radiotherapy and lymphedema in the same patient. Indian Dermatol Online J 2014;5:S101-3.

5. Trombetta M, Erb K, Kudithipudi V, Small J. Bullous pemphigoid appearing as superficial tissue necrosis after irradiation of the breast: Case history and definitive review of the literature. J Solid Tumors 2015;5.

6. Nieder C, Al-Shibli K, Tollåli T. Nontargeted Effect after Radiotherapy in a Patient with Non-Small Cell Lung Cancer and Bullous Pemphigoid. Case Rep Oncol Med 2015;2015:964687.

7. Rejeb M, Moujahed R, Zehani A, Kochbati L. Bullous pemphigoid development during the course of breast can- cer: a radiation induced or a radiation recall dermatitis? J Radiother Pract 2020:1-3.

8. Duschet P, Schwarz T, Gschnait F. Bullous pemphigoid after radiation therapy. J Am Acad Dermatol 1988;18:441-4.

9. Nguyen T, Kwan JM, Ahmed AR. Relationship between radiation therapy and bullous pemphigoid. Dermatology 2014;229:88-96.

10. Moher D, Liberati A, Tetzlaff J, Altman DG; PRISMA Group. Preferred reporting items for systematic reviews and meta-analyses: the PRISMA statement. BMJ. 2009 Jul 21;339:b2535.

11. Campa M, Mansouri B, Wilcox B, Griffin JR. Radiation-induced localized bullous pemphigoid in a patient with breast carcinoma. Dermatol Online J 2016;22.

12. Shon W, Wada DA, Kalaaji AN. Radiation-induced pemphigus or pemphigoid disease in 3 patients with distinct underlying malignancies. Cutis 2016;97:219-22.

13. Kluger N, Mandelin J, Santti K, et al. Bullous pemphigoid triggered by radiotherapy for breast cancer. Presse Med 2017;46:128-30.

14. Hirotsu K, Chiou AS, Chiang A, et al. Localized bullous pemphigoid in a melanoma patient with dual exposure to PD-1 checkpoint inhibition and radiation therapy. JAAD Case Rep 2017;3:404-6.
15. Tanita K, Fujimura T, Kambayashi Y, et al. Intensity-Modulated Radiotherapy Triggers Onset of Bullous Pemphigoid in a Patient with Advanced Melanoma Treated with Nivolumab. Case Rep Oncol 2018;11:114-8.

16. Grimaux X, Delva R, Jadaud E, Croue A. Nivolumab-induced bullous pemphigoid after radiotherapy and abscopal effect. Australas J Dermatol 2019;60:e235-6.

17. Hung T-L, Chen Y-L, Lin K-T, et al. Risk of radiotherapy-associated autoimmune bullous disease among Taiwanese patients with breast cancer: a case-control study. Arch Dermatol Res 2020;312:69-75.

18. Kim J, Jung T, Kim K, et al. Radiation induced pemphigoid disease. Obstet Gynecol Sci 2020;63:750-2.

19. Palleschi GM, Pietro MD, Barzacchi M, et al. A case of laryngeal mucous membrane pemphigoid possibly triggered by radiotherapy. Indian $\mathrm{J}$ Dermatol 2020;65:546.

20. Ashack KA, Kuritza V, Visconti MJ, Ashack L. Dermatologic Sequelae Associated with Radiation Therapy. Am J Clin Dermatol 2020;21:541-55.

21. Mul VEM, van Geest AJ, PijlsJohannesma MCG, et al. Radiationinduced bullous pemphigoid: a systematic review of an unusual radiation side effect. Radiother Oncol 2007;82:5-9. 